\title{
Primary Care Based Intervention Improves Glycated Haemoglobin Level in Type 2 Diabetes Patients: A Pilot Study
}

Jihene Maatoug ${ }^{1}$, Rim Ghammem ${ }^{1 *}$, Imed Harrabi ${ }^{1}$, Sonia Hmad ${ }^{1}$, Mylene Belkacem ${ }^{1}$, Slim Slama $^{2}$, Hanene Khiareddine Gaddour ${ }^{3}$, Abdelhedi Miled ${ }^{4}$, Hassen Ghannem ${ }^{1}$

${ }^{1}$ Department of Epidemiology, University Hospital Farhat Hached

${ }^{2}$ World Health Organization

${ }^{3}$ Sub health manager of the region of Sousse Tunisia

${ }^{4}$ Laboratory of Biochemistry, University Hospital Farhat Hached

Received: : November 26, 2016; Accepted: December 15, 2016; Published: December 31, 2016

*Corresponding author: Rim Ghammem, Department of Epidemiology, University Hospital Farhat Hached 4000 Sousse Tunisia, Tel no: + (216)73219496; E-mail: ghammam.rim2013@gmail.com

\begin{abstract}
Objective: To improve glycemic control among type 2 diabetic patients in primary care level.

Materials and Methods: We conducted a quasi experimental study in primary care centers in the region of Sousse Tunisia with intervention and control groups.

We used the validated Summary of Diabetes Self-Care Activities questionnaire, translated in Arabic and pre-tested to evaluate diet and exercise at baseline and after 6 months. Metabolic control and biomedical measures have been measured at baseline and after $6^{\text {th }}$ month intervention.

The intervention consisted on multidisciplinary intervention with health education concerning healthy lifestyles and medical adherence. We used an individual intervention during the consultation and phone contacts with patients, and collective intervention in meetings with groups of 10 patients.

Results: Type 2 diabetes patients in intervention group improved their diet score, physical activity and foot care score in main variables.

Glycated hemoglobin levels (HbA1c) decreased significantly in intervention group from $9.57 \pm 1.63$ in pre intervention to $8.61 \pm 1.61$ in post intervention. In control group, this evolution wasn't significant.

Total cholesterol and LDL cholesterol level decreased significantly in intervention group but not in control group.

Conclusion: Our intervention proved that multidisciplinary teams with medical doctors, dietician and physical activity teacher could be efficient to improve diabetes management.

Keywords: Diabetes; Disease management; Hemoglobin A; Glycosylated; Diet
\end{abstract}

\section{Introduction}

Worldwide, 3.2 million deaths are attributable to diabetes every year [1]. Almost $80 \%$ of diabetes deaths occur in low- and middle-income countries [2]. Type 2 diabetes comprises $90 \%$ of people with diabetes around the world, and is largely the result of excess body weight and physical inactivity [2].

The overall diabetes prevalence was $15.1 \%$ among Tunisian adults [3]. A study was conducted in Tunisia about the knowledge of type 2 diabetic patients and their condition in order to evaluate the quality of diabetes education in primary health care units in Sousse in 2003. It found that knowledge was satisfactory in only $59 \%$ of the patients [4]. Only, $16.7 \%$ of type 2 diabetes patients were considered well controlled [5].

Medication often has an important role to play but, effective management includes lifestyle measures such as a healthy diet, physical activity, maintaining appropriate weight and not smoking [1]. Furthermore, patients find it difficult to implement and sustain the treatment and lifestyle advice given by healthcare professionals [6-7]. This may in part relate to traditional approaches to management in which patients are passive recipients of care. The acquisition of the relevant skills for successful self management may play a key role in tackling beliefs about health and optimizing metabolic control, risk factors, and quality of life [8-9]. Such programs are characterized by the use of multidisciplinary teams that provide integrated approaches to care, evidence-based care algorithms, and information systems that allow frequent tracking of patient-oriented outcomes and the adjustment of treatments [10-11]. These programs should target not only glycated hemoglobin levels but also cardiovascular risk reduction. In this context, several educational programs have been developed in developed countries [12-13]. However, there are few programs in North Africa and particularly in Tunisia. That's why we propose to implement an intervention study which objective was to improve the quality of care through glycemic control in type 2 diabetic patients. 


\section{Methods}

Study design: Quasi experimental study in primary care centers in the region of Sousse Tunisia with intervention and control groups conducted in 2012.

Study setting: We conducted this study with two groups: Intervention and control. The region of Sousse 1 was designed as intervention zone and Sousse 2 as the control one. There are 10 primary care centers in each zone with chronic disease consultation (diabetes patients). We chose centers to participate to the study according to number of diabetes patients managed in the center, motivation of the team and feasibility of the study. Finally two centers participated to the intervention group and three centers in control group.

Study population: Patients are eligible if they are 18 to 70 years old, have a clinical diagnosis of type 2 diabetes and $\mathrm{HbA1c} \geq$ $7 \%$. We excluded participants if they have diagnosed diabetes for more than 10 years, severe and enduring mental health problems are not primarily responsible for their own care, are unable to participate in a group program.

Sample size: Sample size estimates were based on a twosided significance level of 0.05 and $80 \%$ power to detect betweengroup $1.5 \%$ point difference in glycated hemoglobin level so 55 participants in each group are needed. Assuming a dropout rate of $30 \%$, at least 72 participants in each group are needed to be recruited at pre assessment.

Sampling method/technique: The eligible patients, who consult in the selected centers, since the beginning of the study, have been included. We included respectively 112 and 92 in the intervention and control groups. We excluded patients with HbA1c $<7 \%$, so in the study, we have enrolled respectively 78 and 59 patients in intervention and control groups.

Data collection: Socio-demographic and lifestyle data have been collected by a pre-tested questionnaire administered by a medical doctor. The questionnaire administration has been standardized for all interviewers. It has been administered at baseline and at the end of the intervention meaning after 6 months.

Metabolic control and biomedical measures: hemoglobin A1C levels, blood pressure, body weight, and waist circumference have been measured at baseline and at $6^{\text {th }}$ month.

We used the validated Summary of Diabetes Self-Care Activities questionnaire [14], translated in Arabic and pretested. This questionnaire was been administered by formed interviewers. It contains Diet, Exercise, Blood-Glucose Testing, Foot- Care, and Smoking Status items.

Intervention Program: The intervention consisted on health education concerning healthy lifestyles and medical adherence. The intervention has been delivered by 4 medical doctors working in the primary health care centers, one dietician, two nurses and one medical doctor from the project team who have been trained in diabetes education.
The intervention consisted, for each patient in intervention group, on 2 individual educational sessions with health care medical doctor, 1 collective session animated by dietician and medical doctor from the project team about healthy diet for diabetes patients and 1 collective session animated by nurse and physical activity teacher from the project team about how to do physical activities. We also distributed diabetes guide with basic information about diabetes management for patients. Interventional team contacted patients by telephone twice during the intervention to assist them and coach them to be compliant for their medication and healthy lifestyle. They proposed solution for patients who have difficulties to do physical activity or to adopt suitable diet.

Primary care providers were free to use the intervention tools for the other patients in the intervention centers.

In control group, patients had the usual education that they were supposed to have in routine care.

Data management plan: We used SPSS 10.0 Software for data capture and analyze in the Department of Epidemiology, University Hospital Farhat Hached, Sousse, Tunisia.

We compared Diet, Exercise and Foot-Care score in intervention and control group at baseline and 6th month using paired sample t test.

Likely, we compared metabolic and biomedical measures including glycated hemoglobin.

Ethical considerations: The protocol of the study has been approved by the Ethical Committee of the University Hospital Farhat Hached. All participants signed an informed consent before participating to the study.

\section{Results}

Figure 1 shows the flow diagram of the study.

The majority of type 2 diabetes patients were represented by women with $87.3 \%$ and $75 \%$ respectively in intervention and control group $(\mathrm{p}=0.13)$. The mean age of patients was $52.44 \pm$ 8.21 years and $53.64 \pm 8.69$ years respectively in intervention and control groups $(\mathrm{p}=0.56)$. The proportion of patients with primary level of education was $52.3 \%$ and $51.4 \%$ respectively in intervention and control group $(\mathrm{p}=0.67)$. Characteristics of patients participating in the intervention and control groups are summarized in Table 1.

Type 2 diabetes patients in intervention group improved their diet score significantly in main variables like following an eating plan and eating fruits and vegetables [Table 2]. These scores didn't change significantly in control group.

Table 2 shows that the score of patients who do 30 minutes of physical activity increased significantly both in intervention and control groups. The patients who do physical activity in a specific exercise session didn't increase significantly in intervention group and decrease in control group.

Score of foot care improved in intervention group essentially for checking feet and inspecting inside of shoes [Table 3]. 
HbA1c levels decreased significantly in intervention group from $9.57 \pm 1.63$ in pre intervention to $8.61 \pm 1.61$ in post intervention $(\mathrm{p}<10-3)$. In control group, this evolution wasn't significant $(\mathrm{p}=0.086)$. Total cholesterol and LDL cholesterol level decreased significantly in intervention group but not in control group [Table 4].

Anthropometric measures such as body mass index and waist circumference decreased significantly in intervention and control groups. Systolic blood pressure decreased only in intervention group [Table 4].

\section{Discussion}

Our study demonstrates the effectiveness of the intervention to improve healthy diet compliance, foot care, physical activity and $\mathrm{HbA} 1 \mathrm{c}$ level.

This intervention study to improve diabetes care in primary health care centers represents one of the few intervention studies in Tunisia.

The main focus of the treatment and care for Type 2 diabetes

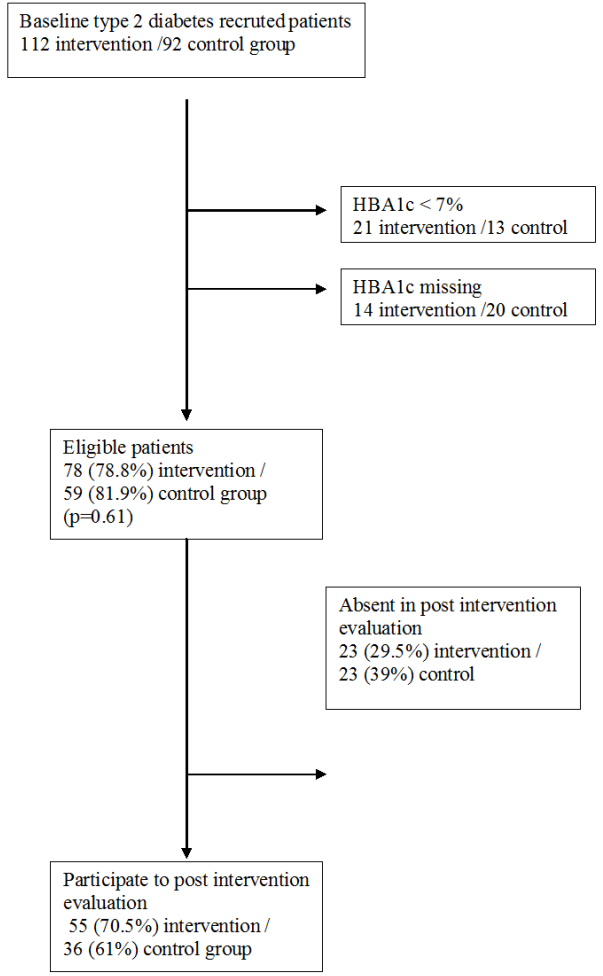

Figure 1: The flow diagram of the study with number of participants and drop out patients.
Table 1: Characteristics of two groups of patients participating in an intervention to improve diabetes self-management in the region of Sousse (Tunisia)

\begin{tabular}{|c|c|c|c|c|}
\hline & & Intervention & Control & $\mathbf{p}$ \\
\hline \multirow{2}{*}{$\begin{array}{c}\text { Gender n } \\
(\%)\end{array}$} & Women & $48(87.3)$ & $27(75.0)$ & \multirow{2}{*}{0.130} \\
\hline & Men & $7(12.7)$ & $9(25.0)$ & \\
\hline \multicolumn{2}{|c|}{ Mean age mean (SD) years } & $52.44(8.21)$ & $53.64(8.69)$ & 0.560 \\
\hline \multirow{3}{*}{$\begin{array}{c}\text { Education } \\
\text { n (\%) }\end{array}$} & Illiterate & $14(31.8)$ & $8(22.9)$ & \multirow{3}{*}{0.670} \\
\hline & Primary & $23(52.3)$ & $18(51.4)$ & \\
\hline & Secondary or more & $7(15.9)$ & $9(25.7)$ & \\
\hline \multicolumn{2}{|c|}{$\begin{array}{c}\text { Medical history of hypertension } \\
\mathrm{n}(\%)\end{array}$} & $19(46.3)$ & $16(51.6)$ & 0.650 \\
\hline \multicolumn{2}{|c|}{$\begin{array}{c}\text { Medical history of dyslipidemia } \\
\mathrm{n}(\%)\end{array}$} & $16(39.0)$ & $7(22.6)$ & 0.138 \\
\hline \multicolumn{2}{|c|}{$\begin{array}{c}\text { Medical history of } \\
\text { cardiovascular disease } \mathrm{n}(\%)\end{array}$} & $2(4.9)$ & $3(9.7)$ & 0.740 \\
\hline \multicolumn{2}{|c|}{$\begin{array}{l}\text { Duration of diabetes mean } \\
\text { (SD) years }\end{array}$} & $4.02(2.61)$ & $4.59(2.43)$ & 0.350 \\
\hline
\end{tabular}

Table 2: Comparison of pre post diet and physical activity scores in intervention and control groups of type 2 diabetic patients in primary health care centers in Sousse Tunisia

\begin{tabular}{|c|c|c|c|c|c|c|}
\hline & \multicolumn{3}{|c|}{ Intervention group } & \multicolumn{3}{|c|}{ Control group } \\
\hline & $\begin{array}{l}\text { Pre } \\
\text { mean } \\
\text { (SD) } \\
\text { days/ } \\
\text { week }\end{array}$ & $\begin{array}{l}\text { Post } \\
\text { mean } \\
\text { (SD) } \\
\text { days/ } \\
\text { week }\end{array}$ & p & $\begin{array}{l}\text { Pre } \\
\text { mean } \\
\text { (SD) } \\
\text { days/ } \\
\text { week }\end{array}$ & $\begin{array}{l}\text { Post } \\
\text { mean } \\
\text { (SD) } \\
\text { days/ } \\
\text { week }\end{array}$ & p \\
\hline $\begin{array}{l}\text { How many of the last } \\
\text { SEVEN DAYS have you } \\
\text { followed a healthful } \\
\text { eating plan? }\end{array}$ & $\begin{array}{l}2.11 \\
(2.89)\end{array}$ & $\begin{array}{l}4.59 \\
(2.89)\end{array}$ & $<10^{-3}$ & $\begin{array}{l}2.15 \\
(2.82)\end{array}$ & $\begin{array}{l}2.91 \\
(2.66)\end{array}$ & 0.210 \\
\hline $\begin{array}{l}\text { On average, over the } \\
\text { past month, how many } \\
\text { DAYS PER WEEK have } \\
\text { you followed your } \\
\text { eating plan? }\end{array}$ & $\begin{array}{l}2.43 \\
(2.96)\end{array}$ & $\begin{array}{l}4.38 \\
(2.82)\end{array}$ & 0.001 & $\begin{array}{l}2.53 \\
(2.88)\end{array}$ & $\begin{array}{l}3.00 \\
(2.81)\end{array}$ & 0.420 \\
\hline $\begin{array}{l}\text { On how many of the } \\
\text { last SEVEN DAYS did } \\
\text { you eat five or more } \\
\text { servings of fruits and } \\
\text { vegetables? }\end{array}$ & $\begin{array}{l}2.23 \\
(2.73)\end{array}$ & $\begin{array}{l}4.21 \\
(2.94)\end{array}$ & 0.001 & $\begin{array}{l}2.82 \\
(9.97)\end{array}$ & $\begin{array}{l}3.56 \\
(2.90)\end{array}$ & 0.320 \\
\hline $\begin{array}{l}\text { On how many of the } \\
\text { last SEVEN DAYS did } \\
\text { you eat high fat foods } \\
\text { such as red meat or } \\
\text { full-fat dairy products? }\end{array}$ & $\begin{array}{l}4.74 \\
(2.41)\end{array}$ & $\begin{array}{l}5.48 \\
(1.98)\end{array}$ & 0.950 & $\begin{array}{l}5.62 \\
(1.96)\end{array}$ & $\begin{array}{l}5.57 \\
(1.84)\end{array}$ & 0.900 \\
\hline $\begin{array}{l}\text { On how many of the } \\
\text { last SEVEN DAYS did } \\
\text { you participate in at } \\
\text { least } 30 \text { minutes of } \\
\text { physical activity? }\end{array}$ & $\begin{array}{l}2.42 \\
(2.77)\end{array}$ & $\begin{array}{l}4.69 \\
(2.57)\end{array}$ & $<10^{-3}$ & $\begin{array}{l}2.88 \\
(3.01)\end{array}$ & $\begin{array}{l}4.21 \\
(2.84)\end{array}$ & 0.020 \\
\hline $\begin{array}{l}\text { On how many of the } \\
\text { last SEVEN DAYS } \\
\text { did you participate } \\
\text { in a specific exercise } \\
\text { session other than } \\
\text { what you do around } \\
\text { the house or as part of } \\
\text { your work? }\end{array}$ & $\begin{array}{l}0.53 \\
(1.78)\end{array}$ & $\begin{array}{l}0.84 \\
(2.05)\end{array}$ & 0.500 & $\begin{array}{l}0.15 \\
(0.49)\end{array}$ & $\begin{array}{l}0.00 \\
(0.00)\end{array}$ & 0.190 \\
\hline
\end{tabular}


is changes in lifestyle, and this requires the individual to be continuously stimulated and aware of the importance of such changes [15]. Type 2 diabetic patients followed in primary care rarely benefit from a structured educational approach in spite of the fact that the intervention of a multidisciplinary team has proven its efficacy for improving metabolic control [16, 17]. The multidisciplinary intervention program is well accepted by patients [16]. In our study we proposed in addition to care interventions, practical exercises and convenient solution to be more active.

Medical doctors called also patients to coach them in their diet, physical activity and treatment compliance which are not expensive actions that allow multiple interventions in a limited period of time [18]. Usually patients find difficulty to implement

Table 3: Comparison of pre post foot care score in intervention and control groups of type 2 diabetic patients in primary health care centers in Sousse Tunisi

\begin{tabular}{|l|c|c|c|c|c|c|}
\hline & \multicolumn{2}{|c|}{ Intervention group } & \multicolumn{3}{c|}{ Control group } \\
\cline { 2 - 7 } & $\begin{array}{c}\text { Pre } \\
\text { mean } \\
\text { (SD) } \\
\text { days/ } \\
\text { week }\end{array}$ & $\begin{array}{c}\text { Post } \\
\text { mean } \\
\text { (SD) } \\
\text { days/ } \\
\text { week }\end{array}$ & p & $\begin{array}{c}\text { Pre } \\
\text { mean } \\
\text { (SD) } \\
\text { days/ } \\
\text { week }\end{array}$ & $\begin{array}{c}\text { Post } \\
\text { mean } \\
\text { (SD) } \\
\text { days/ } \\
\text { week }\end{array}$ & p \\
\hline $\begin{array}{l}\text { On how many of the } \\
\text { last SEVEN DAYS did } \\
\text { you check your feet? }\end{array}$ & $\begin{array}{c}5.13 \\
(2.98)\end{array}$ & $\begin{array}{c}6.75 \\
(0.76)\end{array}$ & $<10^{-3}$ & $\begin{array}{c}5.81 \\
(2.37)\end{array}$ & $\begin{array}{c}6.44 \\
(0.98)\end{array}$ & 0.160 \\
\hline $\begin{array}{l}\text { On how many of the } \\
\text { last SEVEN DAYS did } \\
\text { you inspect the inside } \\
\text { of your shoes? }\end{array}$ & $\begin{array}{c}3.31 \\
(3.38)\end{array}$ & $\begin{array}{c}6.16 \\
(1.57)\end{array}$ & $<10^{-3}$ & $\begin{array}{c}4.00 \\
(3.36)\end{array}$ & $\begin{array}{c}5.50 \\
(2.61)\end{array}$ & 0.020 \\
\hline $\begin{array}{l}\text { On how many of the } \\
\text { last SEVEN DAYS did } \\
\text { you wash your feet? }\end{array}$ & $\begin{array}{c}6.82 \\
(0.89)\end{array}$ & $\begin{array}{c}7.00 \\
(0.00)\end{array}$ & 0.160 & $\begin{array}{c}6.33 \\
(1.79)\end{array}$ & $\begin{array}{c}6.48 \\
(1.69)\end{array}$ & 0.720 \\
\hline $\begin{array}{l}\text { On how many of the } \\
\text { last SEVEN DAYS did } \\
\text { you soak your feet? }\end{array}$ & $\begin{array}{c}3.83 \\
(3.19)\end{array}$ & $\begin{array}{c}4.81 \\
(2.84)\end{array}$ & 0.120 & $\begin{array}{c}5.48 \\
(2.47)\end{array}$ & $\begin{array}{c}4.35 \\
(3.05)\end{array}$ & 0.140 \\
\hline $\begin{array}{l}\text { On how many of the } \\
\text { last SEVEN DAYS } \\
\text { did you dry between } \\
\text { your toes after } \\
\text { washing? }\end{array}$ & $\begin{array}{c}4.84 \\
(3.10)\end{array}$ & $\begin{array}{c}5.80 \\
(2.62)\end{array}$ & 0.060 & $\begin{array}{c}5.03 \\
(2.56)\end{array}$ & $\begin{array}{c}4.64 \\
(2.95)\end{array}$ & 0.470 \\
\hline
\end{tabular}

and sustain the treatment and lifestyle advice given by healthcare professionals [19].This mayin partrelate to traditional approaches to management in which patients are passive recipients of care. The acquisition of the relevant skills for successful self management may play a key role in tackling beliefs about health and optimizing metabolic control, risk factors, and quality of life $[8,20]$. This was our strategy in educating patients by motivating them to improve their compliance to healthy lifestyle. Educating patients about diabetes may have a pivotal role in encouraging and supporting them to assume active responsibility for the day to day control of their condition [21-22]. Such programs are characterized by the use of multidisciplinary teams that provide integrated approaches to care, evidence-based care algorithms, and information systems that allow frequent tracking of patientoriented outcomes and the adjustment of treatments [9-10]. Traditional one-to-one care, although delivered according to optimized criteria, is associated with progressive deterioration of knowledge, problem solving ability, and quality of life. Better cognitive and psychosocial results are associated with more favorable clinical outcomes. A review [23] of interventions to improve the management of diabetes in primary care, outpatient, and community settings found that multifaceted professional interventions and organizational interventions that facilitate structured and regular review of patients were effective in improving the process of care. The addition of patient education to these interventions and the enhancement of the role of nurses in diabetes care led to improvements in patient outcomes and the process of care. So we need, in our context to improve the quality of care and change to psychosocial management of patients. This change needs training of medical doctors and enhancement of the number of health care providers. Managing diabetes or chronic disease by phone could be an interesting alternative in our country.

The contribution of our intervention consists on the use of multidisciplinary teams with medical doctors, dietician and physical activity teacher. Even if our patients didn't have a high education level, they tried to follow healthcare providers. This may be related to the use of easy and practical methods in the different forms of intervention such as phone call or group sessions.

Table 4: Comparison of pre post intervention biomarkers and biometric measures in intervention and control groups of type 2 diabetic patients in primary health care centers in Sousse Tunisia

\begin{tabular}{|c|c|c|c|c|c|c|}
\hline & \multicolumn{3}{|c|}{ Intervention group } & \multicolumn{3}{|c|}{ Control group } \\
\hline & Pre mean (SD) & Post mean (SD) & $\mathbf{p}$ & Pre mean (SD) & Post mean (SD) & $\mathbf{p}$ \\
\hline HbA1c (\%) & $9.57(1.63)$ & $8.61(1.61)$ & $<10^{-3}$ & $10.05(2.16)$ & $9.35(2.54)$ & 0.086 \\
\hline Blood glucose (mmol/l) & $11.40(4.18)$ & $10.64(3.21)$ & 0.180 & $12.68(7.28)$ & $10.53(3.71)$ & 0.090 \\
\hline Total cholesterol (mmol /l) & $5.3(1.30)$ & $4.86(1.19)$ & 0.007 & $5.0(0.73)$ & $4.80(0.64)$ & 0.245 \\
\hline LDL cholesterol (mmol/ l) & $3.03(1.14)$ & $2.61(0.97)$ & 0.008 & $2.68(0.62)$ & $2.79(0.52)$ & 0.230 \\
\hline HDL cholesterol (mmol/ l) & $1.35(0.41)$ & $1.35(0.39)$ & 0.940 & $1.81(0.94)$ & $1.73(0.65)$ & 0.050 \\
\hline Body mass index $\left(\mathrm{Kg} / \mathrm{m}^{2}\right)$ & $31.87(5.43)$ & $31.17(5.38)$ & 0.003 & $33.04(10.29)$ & $32.17(9.77)$ & 0.001 \\
\hline Waist circumference (cm) & $107.02(14.53)$ & $101.46(16.54)$ & 0.040 & $106.88(14.49)$ & $97.5(17.73)$ & 0.010 \\
\hline Systolic blood pressure (mmHg) & 146.1(19.6) & $137.8(20.2)$ & 0.004 & $138.9(22.5)$ & $130.9(16.3)$ & 0.080 \\
\hline $\begin{array}{l}\text { Diastolic blood pressure } \\
\text { (mmHg) }\end{array}$ & $83.3(10.8)$ & $8.08(15.2)$ & 0.210 & $84.0(14.5)$ & $79.8(11.9)$ & 0.200 \\
\hline
\end{tabular}


Most previous diabetes management programs have focused on glycemic control and have reduced glycated hemoglobin (A1C) levels by as much as $1 \%$ to $2 \%$ [23-24]. However, these programs should also address cardiovascular risk reduction if they are to be more beneficial [25]. The improvement of cardiovascular profile will depend not only on the reduction of glycosylated hemoglobin (HbA1c) levels, but also of other factors, such as blood pressure. The Steno-2 study [26] clearly demonstrated that only intensive multifactorial intervention, could promotes sustained beneficial effects on rates of death and cardiovascular disorders in T2DM patients.

The main limit of our study is the number of drop out mainly in control group. This could be explained by the fact that post assessment was made during the summer vacation, the period when people return to their hometowns. The design allowed for a comprehensive evaluation of the data and in a developing country like Tunisia, it is a valuable stepping stone for future programs.

\section{Conclusion}

This intervention study demonstrated that type 2 diabetes patients need better disease management from health care providers to improve their diabetic control. It depends essentially on health professional motivation and help from stakeholders to implement multidisciplinary interventions that seems to be more effective for diabetic control in primary care.

\section{Acknowledgment}

This project was funded by World Health Organization EMRO RPPH Grant 2010/2011_10-9.

\section{Conflicts of interest}

We declare that no conflict of interest, financial or other, exists. My Institute's (Epidemiology department, University Hospital of Farhat Hached, Sousse, Tunisia) representative is fully aware of this submission

\section{Contribution of the authors}

All authors of this research paper have directly participated in the planning, execution, or analysis of this study.

\section{References}

1. Diabetes action now: an initiative of the World Health Organization and the International Diabetes Federation. WHO. 2004.

2. WHO. Fact sheet $\mathrm{N}^{\circ} 312$; November 2009. https://www.scribd.com/ document/169985832/WHO-Diabetes-Fact-Sheet. 2009

3. Ben Romdhane H, Ben Ali S, Aissi W, Traissac P, Aounallah-Skhiri $\mathrm{H}$, Bougatef $\mathrm{S}$, et al. Prevalence of diabetes in Northern African countries: the case of Tunisia. BMC Public Health. 2014;14:86. doi: 10.1186/1471-2458-14-86.

4. Ben Abdelaziz A, Thabet H, Soltane I, Gaha K, Gaha R, Tlili H, et al. Knowledge of patients with type 2 diabetes about their condition in Sousse, Tunisia. East Mediterr Health J. 2007;13(3):505-14.

5. Ben Abdelaziz A, Soltane I, Gaha K, Thabet H, Tlili H, Ghannem H. [Predictive factors of glycemic control in patients with type 2 diabetes mellitus in primary health care]. Rev Epidemiol Sante Publique. 2006;54(5):443-52.

6. Khunti K, Gray LJ, Skinner T, Carey ME, Realf K, Dallosso H, et al. Effectiveness of a diabetes education and self management programme (DESMOND) for people with newly diagnosed type 2 diabetes mellitus: three year follow-up of a cluster randomised controlled trial in primary care. BMJ. 2012;344:e2333. doi: 10.1136/bmj.e2333.
7. Shakibazadeh E, Larijani B, Shojaeezadeh D, Rashidian A, Forouzanfar M, Bartholomew L. Patients' Perspectives on Factors that Influence Diabetes Self-Care. Iran J Public Health. 2011;40(4):146-58.

8. Skinner TC, Cradock S, Arundel F, Graham W. Four Theories and a Philosophy: Self-Management Education for Individuals Newly Diagnosed With Type 2 Diabetes. Diabetes Spectr. 2003;16:75-80.

9. Fitzner K, Greenwood D, Payne H, Thomson J, Vukovljak L, McCulloch A, et al. An assessment of patient education and self-management in diabetes disease management--two case studies. Popul Health Manag. 2008;11(6):329-40. doi: 10.1089/pop.2008.0012.

10. Bodenheimer T, Wagner EH, Grumbach K. Improving primary care for patients with chronic illness. JAMA. 2002 ;288(14):1775-9.

11. Nuovo J, Balsbaugh T, Barton S, Davidson E, Fox-Garcia J, Gandolfo A, et al. Development of a diabetes care management curriculum in a family practice residency program. Dis Manag. 2004;7:314-24.

12. Khunti K, Gray LJ, Skinner T, Carey ME, Realf K, Dallosso H, et al. Effectiveness of a diabetes education and self management programme (DESMOND) for people with newly diagnosed type 2 diabetes mellitus: three year follow-up of a cluster randomised controlled trial in primary care. BMJ. 2012;344:e2333. doi: 10.1136/ bmj.e2333.

13. Solorio R, Bansal A, Comstock B, Ulatowski K, Barker S. Impact of a Chronic Care Coordinator Intervention on Diabetes Quality of Care in a Community Health Center. Health Serv Res. 2015;50(3):730-49. doi: 10.1111/1475-6773.12253.

14.D.J. Toobert, S.E. Hampson, R.E. Glasgow. The Summary of Diabetes Self-Care Activities Measure: results from 7 studies and a revised scale. Diabetes Care. 2000;23(7):943-50.

15. Booth AO, Lowis C, Dean M, Hunter SJ, McKinley MC. Diet and physical activity in the self-management of type 2 diabetes: barriers and facilitators identified by patients and health professionals. Prim Health Care Res Dev. 2013; 14(3):293-306. doi: 10.1017/ S1463423612000412.

16. Freyens A, Brendel F, Maassen C, Cogniaux S, Giet D. [Multidisciplinary educational health programme for type 2 diabetic patients in primary care]. Rev Med Liege. 2005;60(5-6):604-11.

17. Willens D, Cripps R, Wilson A, Wolff K, Rothman R. Interdisciplinary Team Care for Diabetic Patients by Primary Care Physicians, Advanced Practice Nurses, and Clinical Pharmacists. Clin Diabetes. 2011;29:608.

18. Eakin EG, Reeves MM, Lawler SP, Oldenburg B, Del Mar C, Wilkie $\mathrm{K}$, et al. The Logan Healthy Living Program: a cluster randomized trial of a telephone-delivered physical activity and dietary behavior intervention for primary care patients with type 2 diabetes or hypertension from a socially disadvantaged community--rationale, design and recruitment. Contemp Clin Trials. 2008;29(3):439-54.

19. Morris AD. Considerations in assessing effectiveness and costs of diabetes care: lessons from DARTS. Diabetes Metab Res Rev. 2002;18 Suppl 3:S32-5.

20. Norris SL, Lau J, Smith SJ, Schmid CH, Engelgau MM. Self-Management Education for Adults With Type 2 Diabetes: A meta-analysis of the effect on glycemic control. Diabetes Care. 2002;25(7):1159-71.

21.The-delivery-strategy-for-the-National-Service-Framework-forDiabetes. http://www.nursingtimes.net/Journals/2012/10/05/b/ f/t/030415The-delivery-strategy-for-the-National-Service-Framework-for-Diabetes.pdf 
22. Rutten G. Diabetes patient education: time for a new era. Diabet Med. 2005;22(6):671-3.

23. Renders CM, Valk GD, Griffin SJ, Wagner EH, Eijk Van JT, Assendelft WJ. Interventions to improve the management of diabetes in primary care, outpatient, and community settings: a systematic review. Diabetes Care. $2001 ; 24(10)$ :1821-33.

24. The Community Guide. The Guide to Community Preventive Services: What Works to Promote Health?. http://www.thecommunityguide. org/diabetes/Diabetes.pdf
25. Ku G, Kegels G. Integrating chronic care with primary care activities: enriching healthcare staff knowledge and skills and improving glycemic control of a cohort of people with diabetes through the First Line Diabetes Care Project in the Philippines. Glob Health Action. 2014;7:25286. doi: 10.3402/gha.v7.25286.

26. Gaede PH, Jepsen PV, Larsen JNB, Jensen GV, Parving H-H, Pedersen OB. The Steno-2 study. Intensive multifactorial intervention reduces the occurrence of cardiovascular disease in patients with type 2 diabetes. Ugeskr Laeger. 2003;165(26):2658-61. 